\title{
Van İlinde Satışa Sunulan Polenlerin Aflatoksin İçerikleri**
}

\author{
Fatih ARSLAN ${ }^{1}$, Hisamettin DURMAZ ${ }^{2 *}$ \\ ${ }^{1}$ Van Gıda Kontrol Laboratuvar Müdürlüğü, Van, Türkiye. \\ ${ }^{2}$ Harran Üniversitesi, Veteriner Fakültesi, Gıda Hijyeni ve Teknolojisi Anabilim Dalı, Şanlıurfa, Türkiye.
}

Geliș Tarihi: 29.11.2018

Kabul Tarihi: 18.06.2019

Özet: Bu çalışmada, Van ilinde üretilen 35 adet polen örneğinin rutubet miktarı, su aktivitesi içeriği ve pH değerleri ile aflatoksin içerikleri araştırılmıştır. Polen örneklerindeki aflatoksin $B_{1}, B_{2}, G_{1}$ ve $G_{2},\left(A F B_{1}, A F B_{2}, A F G_{1}\right.$ ve $\left.A F G_{2}\right)$ miktarları yüksek performanslı sıvı kromatografisi (HPLC) ile belirlenmiştir. Yapılan araştırmada polen örneklerinin rutubet miktarı \%7.35 ile \%11.41 arasında değişiklik göstermiş olup ortalama \%9.46 \pm 0.18 olarak belirlenmiştir. Polen örneklerinin ortalama su aktivitesi (aw) içeriği $0.28 \pm 0.01$ olarak tespit edilmiş olup 0.24 ile 0.45 arasında değişiklik göstermiştir. pH değerleri ise 3.91'den 5.50'ye kadar farklılık göstermiş ve ortalama 4.38 \pm 0.06 olarak tespit edilmiştir. Örneklerin hiçbirinde AFB $_{1}$ tespit edilemezken, $\mathrm{AFB}_{2}$ düzeyleri $0-0.24 \mu \mathrm{g} / \mathrm{kg}$ arasında dağılım göstermiştir (ortalama $0.01 \pm 0.01 \mu \mathrm{g} / \mathrm{kg}$ ). Polen örneklerinin toplam aflatoksin düzeylerinin minimum, maksimum ve ortalama değerleri sırasıyla $0,2.84$ ve $0.34 \pm 0.13 \mu \mathrm{g} / \mathrm{kg}$ olarak belirlenmiştir. Örneklerin aflatoksin düzeyi ile rutubet miktarları arasında düşük fakat istatistiksel olarak önemli bir korelasyon ( $r$ : 0.41) bulunmuştur. Çalışma sonucunda, incelenen toplam 35 polen örneklerinin 23'ünde (\%66) aflatoksin saptanmış ve belirlenen aflatoksin miktarının Türk Gıda Kodeks'ine göre kabul edilebilir limitler içerisinde olduğu tespit edilmiştir. İncelenen polen örneklerindeki rutubet düzeyinin artışına bağı olarak toplam aflatoksin düzeylerindeki artış yüksek aflatoksin içeriğinin depolama şartlarından kaynaklandığını düşündürmektedir.

Anahtar Kelimeler: Aflatoksin, Polen, Van.

\section{Aflatoxin Contents of Pollens Sold in Van Province}

Abstract: The objective of this study was to investigate moisture content, water activity, $\mathrm{pH}$ value and aflatoxin contents of pollen samples ( $n$ : 35) collected in Van province of Turkey. Aflatoxin $B_{1}, B_{2}, G_{1}$ and $G_{2}\left(A_{F B}, A_{1 F B}, A F G_{1}\right.$ and $\left.A F G_{2}\right)$ contents of the pollen samples were detected by high-performance liquid chromatography (HPLC). The moisture contents varied from $7.35 \%$ up to $11.41 \%$ with an average of $9.46 \pm 0.18 \%$. The average water activity (aw) was determined as $0.28 \pm 0.01$ varying between 0.24 and 0.45 . The $\mathrm{pH}$ value varied from 3.91 to 5.50 and averaged $4.38 \pm 0.06$. While $\mathrm{AFB}_{1}$ was not detected in any of the samples $\mathrm{AFB}_{2}$ content varied between 0.00 and $0.24 \mu \mathrm{g} / \mathrm{kg}$ with an average of $0.01 \pm 0.01 \mu \mathrm{g} / \mathrm{kg}$. The minimum, maximum and mean value of total aflatoxin level was determined as $0,2.84$ and $0.34 \pm 0.13 \mu \mathrm{g} / \mathrm{kg}$, respectively. A low but statistically significant correlation $(r=0.41)$ between the total aflatoxin and moisture content was found $(P<0.05)$. As a result, aflatoxin was detected in $23(66 \%)$ of the 35 pollen samples tested, and the amount of aflatoxin was found within the ranges permitted by the Turkish Food Codex. The positive correlation between the moisture content the aflatoxin content of the pollen samples examined suggested that the high aflatoxin levels observed might due to inappropriate storage condition.

Keywords: Aflatoxin, Pollen, Van.

\section{Giriş}

Türkiye nüfusunun yarısından fazlası tarım ile uğraşmasına rağmen her geçen yıl gayri safi milli hasılada tarımın payı gittikçe düşmektedir. Günümüzde bu oranın \%6.5-12.0 arasında kalması bile tarımdan elde edilen gelirin ve kalitenin iyi olmadığını göstermektedir. Türkiye'de arıcılık konusunda devlet desteği çeşitli şekillerde yapılmakta ve bu desteklemelerden bütün arıcıların faydalanması konusunda hassasiyet gösterilmektedir. III Tarım ve Orman Müdürlükleri, Ziraat Bankası ve Tarım Kredi Kooperatifleri desteklemeler ve teşvikler konusunda gerekli olan bilgileri arıcılara verebilmektedirler (Sağlam, 2011). Tarımda kalite ve ürün miktarının artmasına sebep olacak en önemli yollardan biri de arılar tarafından tozlaşmanın sağlanmasıdır. Polen toplamak için çiçeğe giden arılar bitki türlerinde çeşitliliğe ve miktar oranlarının artmasına neden olmaktadır (Kumova ve Özkütük, 1988).

Ülkemizde genelde sabit arıcılık faaliyetleri yerine gezginci arıcılık tercih edilmekte olup arıcıların büyük bir çoğunluğu yalnızca bal üretimi yapmaktadır. Diğer arı ürünlerinin (Polen, arı sütü, balmumu ve propolis gibi) üretimi bala oranla çok az olmasına rağmen, günümüzde özellikle tedavi amaçlı olarak talep edilmekte ve profesyonel arıcılar tarafından polen ve arı sütü üretiminin arttırılması sağlanmaktadır (Kumova ve Korkmaz, 1999).

Arılar poleni, hem genç larvaların hem de yaşlı larvaların beslenmesinde kullanmaktadırlar. Günümüzde polen, arılar kadar insanlar için de önemli bir besin kaynağı olarak kullanılmaktadır (Alataş ve ark., 1997). Son yıllarda, polen tüketimine olan ilgide artış görülürken, diğer taraftan kayıt dışı 
ve denetlenmeyen üreticilerin varlığı da artış göstermektedir. Bu nedenle polen tüketimi gittikçe riskli bir durum arz etmektedir. Polen, çiçeklerin açtığı ve hava sıcaklığının yüksek olduğu ilkbahar ve yaz mevsimlerinde elde edilmektedir. Kurutulması sırasında polenin nem içeriğinin ölçülmesi ve tüketime sunulacak polenin nem oranının \%3-7 arasında olması mikrobiyolojik üreme açısından önem arz etmektedir (Çankaya ve Korkmaz, 2008). Aksi takdirde protein ve karbonhidrat değerinin yüksek olması nedeni ile polenlerde küf üremesinde artış olabilir ve bu küfler aflatoksin üretebilirler.

Aflatoksinler, depolanmış yem ve yem maddelerinde, besinlerde ve doğada yaygın bir şekilde bulunur. Ayrıca, üremeleri için sıcak (25$30^{\circ} \mathrm{C}$ ) ve rutubetli ortamlarda muhafaza edilen besin ve yemlerde hızla gelişip toksin sentezi yapabilirler (Erol, 2007). Dolayısıyla kayıt dışı üretilen ve denetlenmeyen bu üretimlerde aflatoksin varlığının insanların sağlığı için bir tehlike oluşturduğu tahmin edilmektedir. Yapılan bu çalışmayla Van ilinde üretilen polenlerde aflatoksin varlığının halk sağlığı açısından tehlike oluşturup oluşturmadığı incelenmiştir.

\section{Materyal ve Metot}

Materyal: $\mathrm{Bu}$ çalışmada, polen örnekleri alınabilecek arıcılar tespit edilmiş ve üretim yerine gidilerek Van ilinde 13 ilçeden 35 farklı arıcıdan aseptik şartlarda TS EN ISO 948 ve TS EN ISO 16050'ye göre toplam 35 adet polen örneği (her bir arıcıdan 1 adet $50 \mathrm{~g}$ ) alınmıştır (Anonim, 2009; Anonim, 2013).

Rutubet, su aktivitesi ve pH değerlerinin belirlenmesi: Örneklerdeki rutubet içeriğini belirlemek amacıyla AOAC (1997) tarafından önerilen 925.45B metodu kullanıldı ve her bir polen örneğinden $3 \mathrm{~g}$ alınarak etüvde $105^{\circ} \mathrm{C}^{\prime}$ de 3 saat bekletildi, soğuduktan sonra tartıldı ve rutubet içeriği belirlendi. Su aktivitesi $\left(a_{w}\right)$ değerleri için her bir polen örneği su aktivitesi tayin cihazına (Novasina, ms1- $a_{w}$, İsviçre) direkt olarak yerleştirilerek $25^{\circ} \mathrm{C}^{\prime}$ de ölçüldü. $\mathrm{pH}$ değerinin belirlenmesinde ise $5 \mathrm{~g}$ polen örneği alınarak $20 \mathrm{ml}$ ultra saf su içerisinde sulandırıldı ve homojenize edildikten sonra digital pH-metre (Hanna 2211, Romanya) ile ölçüldü.

Aflatoksin $B_{1}, B_{2}, \quad G_{1}$ ve $G_{2}$ standartlarının hazırlanması: Aflatoksin standartlarını hazırlarken öncelikle ana stok hazırlandı. illk aşamada içerisinde $2600 \mathrm{mg}$ toplam aflatoksin bulunan (1000 mg $B_{1}$ $1000 \mathrm{mg} \mathrm{G}_{1}, 300 \mathrm{mg} \mathrm{B}$, $300 \mathrm{mg} \mathrm{G}_{2}$ ) stok çözeltiden $1 \mathrm{ml}$ şilifli şişeye alındı üzerine $9 \mathrm{ml}$ metanol (HPLC saflığında) eklenerek karıştırıldı ve elde edilen konsatrasyon ana stok olarak adlandırıldı. 10 kat seyreltişmiş olan ana stok örneğin içinde $100 \mathrm{mg} B_{1}$, $100 \mathrm{mg} \mathrm{G}, 30 \mathrm{mg} B_{2}, 30 \mathrm{mg} \mathrm{G}$ bulunmaktadır ve daha sonra bu ana stoktan 8 tane ara stok hazırlanarak kalibrasyon eğrisi çizildi (Şekil 1).

Aflatoksin miktarlarının belirlenmesi: Analiz amacıyla homojen hale getirilen örneklerden $25 \pm 0.1 \mathrm{~g}$ tartıldı, blenderin parçalayıcı haznesinde $5 \mathrm{~g}$ sodyum klorür ve $125 \mathrm{ml}$ özütleme çözeltisi $(87.5 \mathrm{ml}$ metanol+37.5 ml ultra saf su) eklenerek karışım yüksek hızda 2 dakikada homojen hale getirildi. Elde edilen homojen karışım kaba oluklu filtre kâğıdından süzülerek berrak bir süzüntü elde edildi.

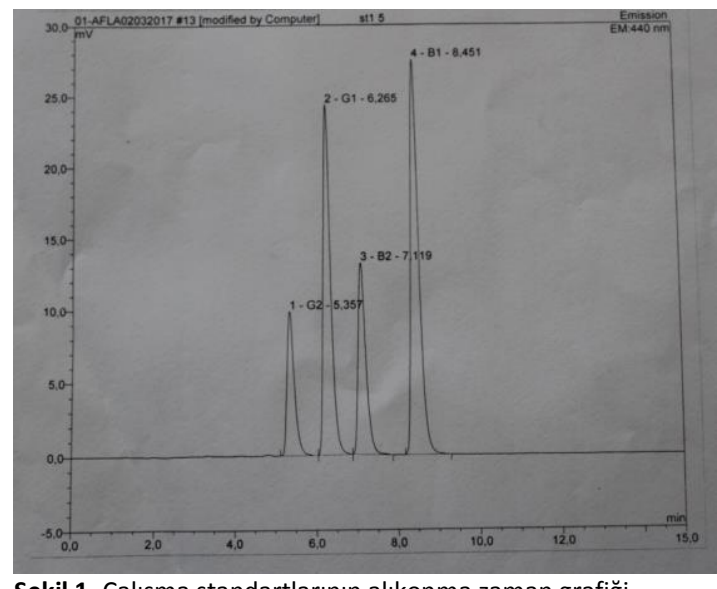

Şekil 1. Çalışma standartlarının alıkonma zaman grafiği.

Berrak bir süzüntü elde edilemeyenlerde ise süzme işlemi tekrarlandı. Örneklerdeki aflatoksinler ekstrakte edilip, elde edilen süzüntüden $5 \mathrm{ml}$ alındı ve daha sonra üzerine $10 \mathrm{ml}$ ultra saf su ilave edilerek immunoaffinite kolondan geçirildi. Bu işlem bağlanmayan pigmentleri uzaklaştırmak için yapıldı. Saflaştırılan toksinler immunoaffinite kolondan $1 \mathrm{ml}$ HPLC saflığında metanolle (\%99'luk konsantrasyonda) geçirilerek viale aktarıldı, üzerine $1 \mathrm{ml}$ ultra saf su ilave edildi ve bu vialdeki karışım homojenize edildi. Daha sonra viallerin kapakları kapatılarak enjeksiyon için HPLC cihazına yerleştirildi.

Tayin: Nicel tayin pik alanının birleştirilmesi veya pik yüksekliği standart maddeye ait ilgili değer ile ilişkilendirildi. Enjektör imalatçısının talimatlarına göre standart çözeltiden $50 \mu l^{\prime}$ lik hacim enjeksiyon haznesine enjekte edildi. Aflatoksinler $G_{2}, G_{1}, B_{2}$ ve $B_{1}$ sırasıyla yaklaşık, $6,8,9$ ve 11 dakika alıkonma zamanları ile birlikte elüte edildi ve taban çizgisine göre ayırt edilebilir olduğuna dikkat edildi. Gerektiğinde hareketli fazın metanol konsantrasyonu değiştirilerek alıkonma süreleri ayarlandı. 
İstatistiksel analiz: Verilerin normal dağılıma uygunluğu Shapiro-wilks testi ile değerlendirilmiştir. Veriler arasındaki korelasyonlar ise Spearman's rho testi ile belirlenmiştir. Verilerin analizinde SPSS (1991) paket programı kullanılmıştır.

\section{Bulgular}

Araştırmada kullanılan örneklerdeki rutubet, su aktivitesi ve $\mathrm{pH}$ değerleri Tablo 1 'de verilmiştir. Rutubet içeriği \%7.35 ile \%11.41 arasında değişiklik göstermiş olup ortalama $\% 9.46 \pm 0.18$ olarak belirlenmiştir.

Tablo 1. Polen örneklerinin kimyasal analiz sonuçları.

\begin{tabular}{llll}
\hline Örnekler & $\begin{array}{c}\text { Rutubet } \\
(\%)\end{array}$ & $\mathbf{a}_{\mathbf{w}}$ & $\mathbf{p H}$ \\
\hline Polen1 & 10.26 & 0.28 & 4.10 \\
Polen2 & 9.19 & 0.29 & 4.11 \\
Polen3 & 9.16 & 0.27 & 4.09 \\
Polen4 & 10.12 & 0.25 & 3.95 \\
Polen5 & 8.70 & 0.25 & 4.35 \\
Polen6 & 10.20 & 0.24 & 3.91 \\
Polen7 & 11.33 & 0.27 & 4.35 \\
Polen8 & 11.18 & 0.25 & 4.33 \\
Polen9 & 11.08 & 0.28 & 4.83 \\
Polen10 & 10.42 & 0.31 & 4.50 \\
Polen11 & 9.14 & 0.40 & 4.09 \\
Polen12 & 11.41 & 0.35 & 4.75 \\
Polen13 & 11.05 & 0.45 & 4.53 \\
Polen14 & 9.28 & 0.27 & 4.25 \\
Polen15 & 8.70 & 0.25 & 4.47 \\
Polen16 & 10.01 & 0.28 & 4.03 \\
Polen17 & 8.29 & 0.25 & 4.85 \\
Polen18 & 8.37 & 0.26 & 4.95 \\
Polen19 & 9.92 & 0.28 & 4.15 \\
Polen20 & 10.58 & 0.25 & 4.30 \\
Polen21 & 9.83 & 0.26 & 4.22 \\
Polen22 & 9.84 & 0.27 & 4.05 \\
Polen23 & 9.13 & 0.25 & 4.52 \\
Polen24 & 8.29 & 0.27 & 4.60 \\
Poeln25 & 9.28 & 0.26 & 4.25 \\
Polen26 & 9.26 & 0.28 & 3.95 \\
Polen27 & 9.10 & 0.25 & 4.70 \\
Polen28 & 9.61 & 0.27 & 4.20 \\
Polen29 & 7.35 & 0.27 & 5.50 \\
Polen30 & 7.80 & 0.26 & 5.03 \\
Polen31 & 8.26 & 0.26 & 4.25 \\
Polen32 & 8.63 & 0.27 & 4.45 \\
Polen33 & 8.57 & 0.27 & 4.30 \\
Polen34 & 9.18 & 0.27 & 4.33 \\
Polen35 & 8.54 & 0.28 & 4.05 \\
\hline Ortalama & 9.46 & 0.28 & 4.38 \\
Minimum & 7.35 & 0.24 & 3.91 \\
Maksimum & 11.41 & 0.45 & 5.50 \\
Standart hata & 0.18 & 0.01 & 0.06 \\
\hline & & &
\end{tabular}

Ortalama su aktivitesi $\left(a_{w}\right) \quad 0.28 \pm 0.01$ olarak tespit edilmiş ve 0.24 ile 0.45 arasında değişiklik tespit edilmiştir. Örneklerin $\mathrm{pH}$ değerleri ise 3.91'den 5.50'ye kadar farklılık göstermiş ve ortalama $4.38 \pm 0.06$ olarak belirlenmiştir. Örneklerin hiçbirinde aflatoksin $B_{1}\left(A F B_{1}\right)$ tespit edilememiştir.
Aflatoksin $\mathrm{B}_{2}\left(\mathrm{AFB}_{2}\right)$ ise $0-0.24 \mu \mathrm{g} / \mathrm{kg}$ arasında olup ortalama $0.01 \pm 0.01 \mu \mathrm{g} / \mathrm{kg}$ olarak belirlenmiştir. Toplam aflatoksin seviyesinin minimum, maksimum ve ortalama değerleri sırasıyla $0,2.84$ ve $0.34 \pm 0.13$ $\mu \mathrm{g} / \mathrm{kg}$ olarak belirlenmiştir (Tablo 2). İstatistiksel analiz sonuçlarına göre toplam aflatoksin ile rutubet miktarı arasında orta derecede ( $r$ : 0.41) bir korelasyon olduğu tespit edilmiştir (Tablo 3).

\section{Tartışma ve Sonuç}

Yüksek derecelerde besleyici maddeleri ihtiva eden taze polenler yaklaşık \%20-30 rutubet oranlarına sahip olup bu özellikleri ile birçok mikroorganizmanın ve özellikle maya-küflerin gelişip çoğalması için iyi bir ortam oluşturmaktadırlar. Bu nedenle polenler bozulmayı önlemek ve raf ömrünü uzatmak için en kısa sürede hasat edilip kurutma aşamasına hazır hale getirilmelidirler. Arıcılar polenleri günlük olarak toplamazlar ve bunun bir sonucu olarak higroskopik olan polenler yüksek derecede çevreden rutubet çekerler (Bogdanov, 2012).

Tablo 2. Polen örneklerindeki aflatoksin miktarları ( $\mu \mathrm{g} / \mathrm{kg}$ ).

\begin{tabular}{|c|c|c|c|c|c|}
\hline Örnekler & $\mathrm{AFB}_{1}$ & $\mathrm{AFB}_{2}$ & $\mathrm{AFG}_{1}$ & $\mathrm{AFG}_{2}$ & $\begin{array}{c}\text { Toplam } \\
\left(B_{1}+B_{2}+G_{1}+G_{2}\right)\end{array}$ \\
\hline Polen1 & 0.00 & 0.00 & 2.76 & 0.00 & 2.76 \\
\hline Polen2 & 0.00 & 0.00 & 0.04 & 0.00 & 0.04 \\
\hline Polen3 & 0.00 & 0.00 & 0.00 & 0.00 & 0.00 \\
\hline Polen4 & 0.00 & 0.00 & 0.01 & 0.00 & 0.01 \\
\hline Polen5 & 0.00 & 0.00 & 0.00 & 0.00 & 0.00 \\
\hline Polen6 & 0.00 & 0.00 & 0.00 & 0.00 & 0.00 \\
\hline Polen7 & 0.00 & 0.00 & 0.68 & 0.00 & 0.68 \\
\hline Polen8 & 0.00 & 0.00 & 0.00 & 0.00 & 0.00 \\
\hline Polen9 & 0.00 & 0.00 & 2.16 & 0.00 & 2.16 \\
\hline Polen10 & 0.00 & 0.00 & 0.00 & 0.00 & 0.00 \\
\hline Polen11 & 0.00 & 0.24 & 0.00 & 0.00 & 0.24 \\
\hline Polen12 & 0.00 & 0.00 & 0.00 & 0.00 & 0.00 \\
\hline Polen13 & 0.00 & 0.00 & 0.00 & 0.36 & 0.36 \\
\hline Polen14 & 0.00 & 0.00 & 0.00 & 0.00 & 0.00 \\
\hline Polen15 & 0.00 & 0.00 & 0.00 & 0.00 & 0.00 \\
\hline Polen16 & 0.00 & 0.21 & 0.00 & 2.64 & 2.84 \\
\hline Polen17 & 0.00 & 0.00 & 0.00 & 0.00 & 0.00 \\
\hline Polen18 & 0.00 & 0.00 & 0.00 & 0.34 & 0.35 \\
\hline Polen19 & 0.00 & 0.00 & 0.00 & 0.00 & 0.00 \\
\hline Polen20 & 0.00 & 0.00 & 0.00 & 1.24 & 1.24 \\
\hline Polen21 & 0.00 & 0.00 & 0.09 & 0.00 & 0.09 \\
\hline Polen22 & 0.00 & 0.00 & 0.00 & 0.00 & 0.00 \\
\hline Polen23 & 0.00 & 0.00 & 0.00 & 0.00 & 0.00 \\
\hline Polen24 & 0.00 & 0.00 & 0.00 & 0.00 & 0.00 \\
\hline Poeln25 & 0.00 & 0.05 & 0.00 & 0.00 & 0.05 \\
\hline Polen26 & 0.00 & 0.00 & 0.00 & 0.00 & 0.00 \\
\hline Polen27 & 0.00 & 0.00 & 0.00 & 0.00 & 0.00 \\
\hline Polen28 & 0.00 & 0.00 & 0.00 & 0.74 & 0.74 \\
\hline Polen29 & 0.00 & 0.00 & 0.00 & 0.00 & 0.00 \\
\hline Polen30 & 0.00 & 0.00 & 0.00 & 0.00 & 0.00 \\
\hline Polen31 & 0.00 & 0.00 & 0.00 & 0.00 & 0.00 \\
\hline Polen32 & 0.00 & 0.00 & 0.17 & 0.00 & 0.17 \\
\hline Polen33 & 0.00 & 0.00 & 0.00 & 0.00 & 0.00 \\
\hline Polen34 & 0.00 & 0.00 & 0.00 & 0.00 & 0.00 \\
\hline Polen35 & 0.00 & 0.00 & 0.00 & 0.00 & 0.00 \\
\hline Ortalama & 0.00 & 0.01 & 0.17 & 0.15 & 0.34 \\
\hline Minimum & 0.00 & 0.00 & 0.00 & 0.00 & 0.00 \\
\hline Maksimum & 0.00 & 0.24 & 2.76 & 2.64 & 2.84 \\
\hline Standart hata & 0.00 & 0.01 & 0.10 & 0.08 & 0.13 \\
\hline
\end{tabular}

Polenlerde renk bozukluğu ve kimyasal reaksiyonlar (maillard reaksiyonu ve lipid oksidasyonu) oluşup, kötü koku ve acı tada neden olduğundan dolayı \%3'den az rutubet oranı arzu edilmez (Serra Bonvehi ve ark., 1991). Bu nedenle kurutulmuş polenlerin rutubet içeriği \%4-8 arasında 
olması gerektiği bildirilmiştir (Melo ve AlmeidaMuradian, 2011; Mutsaers ve ark., 2005). Brezilya, Arjantin, Sırbistan ve Çin gibi ülkelerde kurutulmuş polenlerde maksimum rutubet içeriği sırasıyla, \%4, $\% 4, \% 8$ ve \%10 olarak belirlenmiştir (GB/T 193302003, 2003; Krell, 1996; Službeni list SCG 45, 2003). $\mathrm{Bu}$ çalışmada elde edilen rutubet miktarları yönünden örneklerin \%5.7'si Sırbistan mevzuatlarına ve \%68.5'i ise Çin mevzuatlarına uygun olduğu tespit edilmiştir. Ayrıca bu çalışmada belirlenen rutubet miktarları Nogueira ve ark. (2012)'nın polenler üzerine yapmış oldukları çalışmada belirledikleri rutubet değerleri (\%6.028.40) ile benzerlik göstermiştir. Buna karşın tespit edilen sonuçlar, Brezilya ve Arjantin resmi mevzuatlarındaki ticari arı polenleri için belirlenen limitlerin üzerinde bulunmuştur. Polen örneklerindeki yüksek rutubet içeriği uygun olmayan muhafaza şartlarından kaynaklanmış olabilir. Polenler nadiren vakumlu plastik poşetlerde saklanır ve genellikle uygulanan dondurma ve çözündürme işlemleri rutubet içeriğini olumsuz yönde etkileyebilir. İstatistiksel analiz sonuçlarına göre ise toplam aflatoksin ile rutubet miktarı arasında orta derecede ( $r$ : 0.41) bir korelasyon olduğu tespit edilmiş olup, yüksek rutubet değerlerine sahip örneklerde daha fazla oranda aflatoksin belirlenmiştir (Tablo 3). Bu sonuçlar kurutma ve depolama şartlarında daha düşük rutubet oranlarının gerekliliğini göstermektedir.

Tablo 3. Toplam aflatoksin düzeyi, su aktivitesi, $\mathrm{pH}$ ve rutubet değerleri arasındaki korelasyon katsayıları.

\begin{tabular}{lccc}
\hline & Aflatoksin & Su aktivitesi & pH \\
\hline Su aktivitesi & 0.22 & & \\
pH & -0.12 & -0.14 & \\
Rutubet (\%) & $0.41^{*}$ & 0.21 & -0.27 \\
\hline$: 0.05$ düzeyinde önemli & & &
\end{tabular}

Fungal gelişme için en önemli çevresel faktörler su aktivitesi (serbest su miktarının ölçülmesi) ve sıcaklıktır (Lacey ve Magan, 1991). Polen gibi dehidre gıdaların hijyenik olarak muhafaza edilebilmesi için su aktivite değerinin 0.30'dan düşük olması gerekmektedir (Serra Bonvehi ve Escolà Jordà, 1997). Bu araştırmada örneklerin su aktivitesi 0.24-0.45 değerleri arasında ve ortalama $0.28 \pm 0.01$ olarak tespit edilmiştir. Belirlenen değer aralığı, dehidre gıdalar için normal sınırlar içerisinde olup Brezilya (0.3-0.5) ve İspanya (0.261-0.280)'da arı polenlerinde belirlenen limitler arasında olduğu görülmektedir (Carpes ve ark., 2009; Serra Bonvehi ve Escolà Jordà, 1997). Tespit edilen su aktivitesi değerleri, Estevinho ve ark. (2012)'nın bildirdikleri 0.32-0.55 değerleri ve Serra Bonvehi ve Escolà Jordà (1997)'nın bildirdikleri ortalama 0.27 değerine benzerlik göstermiştir. Bu çalışmadaki örneklerden tespit edilen su aktivitesi değerleri ürünün mikrobiyolojik stabilitesini sağlamada yeterli olabileceği sonucunu göstermektedir.

Polenlerin $\mathrm{pH}$ değerleri tekstür, stabilite ve raf ömrünü önemli derecede etkiler. Bundan dolayı polenlerin muhafazası esnasında bu değerlerin büyük önemi vardır (González-Martin ve ark., 2007). Bu çalışmada analiz edilen polen örnekleri 3.91-5.50 arasında $\mathrm{pH}$ değerine sahip olup, tamamı asidik özellik göstermiştir. Elde edilen veriler Brezilya mevzuatına ( $\mathrm{pH}$ : 4-6) benzerlik göstermiştir. Ayrıca araştırmamızda elde edilen $\mathrm{pH}$ değerleri, Herbert ve Shimanuki (1978)'nin (3.8-5.9), Bastos ve ark. (2003)'nın (3.7-5.5), Coronel ve ark. (2004)'nın (4.27-6.54) ve Marchini ve ark. (2006)'nın (4.3-5.2) belirledikleri değerlere benzerlik göstermektedir.

Aspergillus flavus tropik ve subtropik bölgelerde daha yaygın görülmektedir. Türkiye'nin birçok bölgesinde çeşitli sebeplerden dolayı rutubet ve sıcaklık, mikroorganizmaların lehinde değişmiş (Çetin ve ark., 2008) ve son yıllarda Van ilinde de iklim değişikliği görülerek sıcaklık ve rutubet değerlerinde artış görülmüştür. Bu durum doğada kontrolsüz bir şekilde kurutulan veya muhafaza edilen polenlerin üzerinde küf mantarlarının üremesini arttırmaktadır. Incelenen örneklerin bir kısmında aflatoksin tespit edilmesi, analiz edilen polenlerin Aspergillus spp. ile kontamine olduğunu düşündürmektedir.

Aspergillus'ların gelişmesinde mısır, soya fasulyesi ve buğdayın önemli bir yeri vardır (Nilüfer ve Boyacıoğlu, 2002; Rustom, 1997). Arılar bu bitkilerden Aspergillus ile kontamine polenleri toplar ve kovana getirirler. Yapılan bir çalışmada buğday, mısır ve soya fasulyesinin bu tip bir kontaminasyona sahip olduğu bildirilmiştir (Niu ve ark., 2011). Diğer bir kontaminasyon kaynağı arıcıların bizzat kendileridir. Polen üretim aşamalarından; toplama, kurutma, paketleme ve muhafaza dönemlerinde arıcılar polenleri kontamine edebilirler. Nitekim Pitta ve Markaki (2010)'nin arı polenleri üzerine yaptığı bir araştırmada kovanlardan alınan polenlerin sıklıkla sonraki aşamalarda aflatoksin ile kontamine olduğunu bildirmiş ve polenlerin aflatoksin ile kontaminasyonunun toplama sonrası arıcılar tarafından olduğu kanaatine varmışlardır.

Ratlar üzerine yapılan çalışmalarda günlük 10 $\mu \mathrm{g} / \mathrm{kg}$ vücut ağırlığı miktarında aflatoksin alımının en tehlikeli sonucunun kanserojen etki olduğu ve akut toksisite değerinin ( $\left(D_{50}\right) 7.2 \mathrm{mg} / \mathrm{kg}$ vücut ağırlığı olduğu bildirilmiştir (Belitz ve ark., 2009). Tablo 2'de örneklerin bir kısmında aflatoksin belirlendiği, maksimum $2.84 \mathrm{\mu g} / \mathrm{kg}$ olarak tespit 
edilen değerin belirtilen limitlerin çok altında olduğu görülmektedir.

Türkiye'de diğer birçok ülkede olduğu gibi gıdalarda aflatoksin kontaminasyonu ile ilgili yasal kısıtlamalar vardır. Türkiye'de hazırlanan Türk Gıda Kodeksi Tebliği (Anonim, 2011)'nde çeşitli gıdalar için $A F B_{1}$, toplam aflatoksin $\left(B_{1}, B_{2}, G_{1}\right.$ ve $\left.G_{2}\right)$ ve aflatoksin $M_{1}\left(A F M_{1}\right)$ ile ilgili sınırlar belirlenmiştir. $\mathrm{Bu}$ tebliğe göre gıdalarda bulunabilecek üst limitler $\mathrm{AFB}_{1}$ için $5 \mathrm{\mu g} / \mathrm{kg}$ ve toplam aflatoksin için 10 $\mu \mathrm{g} / \mathrm{kg}^{\prime}$ dır. Bu çalışmada hiçbir örnekte $\mathrm{AFB}_{1}$ tespit edilememiş ve toplam aflatoksin seviyeleri de izin verilen değerler arasında (0-2.84 $\mu \mathrm{g} / \mathrm{kg})$ bulunmuştur. Her ne kadar insanlar tarafından günde 5-10 g polen tüketimi potansiyel olarak tehlikeli görünmese de mısır, buğday ve süt gibi aflatoksinlerle kontaminasyona maruz kalan diğer gıda maddeleri fazla miktarlarda tüketildiğinde ve bu tür gıdalara aflatoksin içeren polen ilavesiyle günlük kabul edilebilir değerin aşılabileceği unutulmamalıdır. Ayrıca Niu ve ark. (2011), arı yemlerine propolis ilavesiyle aflatoksin toksisitesinin azaltılabildiğini bildirmişlerdir. Bu uygulama insan tüketimi için hazırlanmış polenlerde de benzer bir etkiye sahip olabilir ve bu konunun bilimsel sonuçlar ile ortaya çıkarılması gerekmektedir.

Sonuç olarak, örneklerden bir kısmının aflatoksin grupları ile kontamine olduğu, fakat tespit edilen değerlerin mevzuatta bildirilen maksimum limitlerin altında olduğu ve insan sağlığını olumsuz yönde etkileyecek düzeyde olmadığı belirlenmiştir. Ancak yukarıda da ifade edildiği gibi düşük seviyedeki aflatoksin ile kontamine polenlerin, başka kontamine bir ürüne ilave edilmesi sonucunda maksimum limitleri aşmaya neden olabileceğinden, bu konuda riskli gıda olarak değerlendirilmesi gerekmektedir. Diğer taraftan, rutubet miktarı düşük olan polen örneklerinin aflatoksin içeriklerinin de düşük olduğu saptanmıştır $(P<0.05)$. Dolayısıyla küf mantarlarının aflatoksin sentezinin engellenmesi amacıyla polenlerin uygun şartlarda kurutulması gerekmektedir.

\section{Teşekkür}

$\mathrm{Bu}$ çalışma doktora tezinden hazırlanmış olup, Yüzüncü Yıl Üniversitesi Bilimsel Araştırma Projeleri Komisyonu (Proje No: TYL-2017-6135) tarafından desteklenmiştir.

\section{Kaynaklar}

Alataş I, Yalçın Li, Öztürk Ai, 1997: Arıcılıkta polen üretiminin koloni gelişimine ve bal verimine etkileri. Anadolu J of Aarı, 7, 1, 30-42.

Anonim, 2009: Türk Standartları Enstitüsü-TS EN ISO 948 Baharat ve çeşniler-numune alma standartı, Ankara.
Anonim, 2011: Türk Gıda Kodeksi 2011/28157, Türk Gıda Kodeksi Bulaşanlar Yönetmeliği.

Anonim, 2013: Türk Standartları Enstitüsü-TS EN ISO 16050, Gıda maddeleri-hububat, sert kabuklu yemiş ve bunlardan üretilmiş ürünler içindeki aflatoksin $B_{1}$ ve toplam aflatoksin $\left(B_{1}, B_{2}, G_{1}\right.$ ve $\left.G_{2}\right)$ muhtevasının tayini-yüksek performanslı sIVı kromatografi yöntemi, Ankara.

AOAC, 1997: Official Methods of Analysis of AOAC International, $16^{\text {th }}$ Ed., $3^{\text {rd }}$ Rev., Assoc of Official Analytical Chemists, Gaithersburg, MD.

Bastos DH, Rocha Cl, Cunha IBDS, Carvalho PDO, Torres EA, 2003: Composiçäo e qualidade de pólen apícola comercializado em algumas cidades nos estados de Säo Paulo e Minas Gerais-Brasil. Rev Inst Adolfo Lutz, 62(3), 239-244.

Belitz HD, Grosch W, Schieberle P, 2009: Food Chemistry. Springer-Verlag, Heidelberg.

Bogdanov S, 2012: Pollen production, nutrition and health: a review. Bee Product Science, www.beehexagon.net, Erişim tarihi; 15.11.2017.

Carpes ST, Cabral ISR, Rosalen PL, De Alencar SM, Masson ML, 2009: Caracterização do potencial antimicrobiano dos extratos de pólen apícola da região sul do Brasil. Alimentos E Nutrição, 20, 271277.

Coronel BB, Grasso SC, Pereira G, Fernández A, 2004: Caracterización bromatológica del polen apícola Argentino. Cienc Docencia Tecnol, 15, 141-181.

Çankaya N, Korkmaz A, 2008: Polen. Samsun il Tarım Müdürlüğü Çiftçi Eğitimi ve Yayım Şubesi Yayını, 33, 3-5.

Çetin Ö, Eylen M, Üzen N, 2008: İklim değişikliğine karşı GAP bölgesinde etkin sulama stratejileri. TMMOB İklim Değişimi Sempozyumu, 13-14 Mart, Ankara, 269.

Erol i, 2007: Gıda Hijyeni ve Mikrobiyolojisi, Pozitif matbaacilık, Ankara.

Estevinho LM, Rodrigues S, Pereira AP, Feás X, 2012: Portuguese bee pollen: Palynological study, nutritional and microbiological evaluation. Int $J$ Food Sci Technol, 47, 429-435.

GB/T 19330-2003, 2003: Product of designations of origin or geographicl indication-Raohe (Northeast-China black bee) honey, royal jelly, propolis, bee pollen (in Chinese). General Administration of Quality Supervision, Inspection and Quarantine of the People's Republic of China, Beijing, China.

Gonzalez-Martin I, Hernández-Hierro JM, Barros-Ferreiro N, Marcos CC, García-Villanova RJ, 2007: Use of NIRS technology with a remote reflectance fibre-optic probe for predicting major components in bee pollen. Talanta, 72(3), 998-1003.

Herbert JR, Shimanuki H, 1978: Chemical composition and nutritive value of bee-collected and bee-stored pollen. Apidologie, 9, 33-40.

Krell R, 1996: Value-Added Products from Beekeeping. FAO Agricultural Services Bulletin. No: 124.

Kumova U, Korkmaz A, 1999: Arı ürünleri tüketim davranışları üzerine bir araştırma. Türkiye'de arıcılık sorunları. In: I. Ulusal Arıcilık Sempozyumu, Kemaliye/Erzincan. 
Kumova U, Özkütük K, 1988: Çukurova bölgesinde arıcılığın yapısı. ÇÜ Ziraat Fakültesi Dergisi. 3, 1, 2640.

Lacey J, Magan N, 1991: Fungi colonising cereal grain: their occurrence and water and temperature relationships. In "Cereal Grain Mycotoxins, Fungi and Quality in Drying and Storage" Ed; Chelkowski J, Elsevier Science, Amsterdam, pp. 77-118.

Marchini LC, Reis VDA, Moreti ACCC, 2006: Composição físico-química de amostras de pólen coletado por abelhas africanizadas Apis mellifera (Hymenoptera: Apidae) em Piracicaba, Estado de São Paulo. Ciênc Rural, 36, 949-953.

Melo ILP, Almeida-Muradian LB, 2011: Comparison of methodologies for moisture determination on dried bee pollen samples. Ciência e Tecnologia de Alimentos, 31, 1, 194-197.

Mutsaers M, Blitterswijk H, Leven L, Kerkvliet J, Waerdt J, 2005: Bee Products. Properties, Processing and Marketing. Agromisa Foundation, Wageningen, Netherlands.

Nilüfer D, Boyacıoğlu D, 2002: A comparative study of three different methods for the determinations of aflatoxins in tahini. Journal of Agricultural and Food Chemistry, 50, 3375-3379.

Niu G, Johnson RM, Berenbaum MR, 2011: Toxicity of mycotoxins to honey bees and its amelioration by propolis. Apidologie, 42, 79-87.

Nogueira C, Iglesias A, Fea's X, Estevinho LM, 2012: Commercial bee pollen with different geographical origins: A comprehensive approach. International Journal of Molecular Sciences, 13, 11173-11187.

Pitta M, Markaki P, 2010: Study of aflatoxin $B_{1}$ production by Aspergillus parasiticus in bee pollen of greek origin. Mycotoxin Research, 26, 229-234.
Rustom IYS, 1997: Aflatoxin in food and feed: occurrence, legislation and inactivation by physical methods. Food Chemistry, 59, 57-67.

Sağlam M, 2011: Başlarken. Ordu'da Tarım Dergisi,15(89), 1-8.

Serra Bonvehi J, Escolà Jordà R, (1997): Nutrient composition and microbiological quality of honeybee-collected pollen in Spain. Journal of Agricultural and Food Chemistry, 45(3), 725-732.

Serra Bonvehi J, Escura Pesudo F, Giner Pallares J, (1991): La détermination quantitative des acides aminés libres dans les pollens apicoles à l'aide de la chromatographie en phase gazeuse, chromatographie liquide haute performance et spectrophotométrie. Annales des falsifications, de l'expertise chimique et toxicologique, 84, 897, 153166.

Službeni list SCG 45, 2003: Pravilnik o kvalitetu i drugim zahtevima za med, druge pćelinje proizvode, preparate na bazi meda i drugih pćelinjih proizvoda [Rulebook on quality and other requirements for honey, other bee products and products based on honey and other bee products]. Sluźbenom listu SCG, br. 45/2003 od 17.10.2003. godine, ćlan 31.

SPSS, 1991: Statistical Package for The Social Sciences (SPSS/PC+). Chicago, IL: SPSS Inc.

**: Bu çalışma 2017 yılında Yüzüncü Yıl Üniversitesi Sağlık Bilimleri Enstitüsü Besin Hijyeni ve Teknolojisi Anabilim Dalında yapılan Doktora tezinden özetlenmiştir.

*Yazışma Adresi: Hisamettin DURMAZ

Harran Üniversitesi, Veteriner Fakültesi, Besin Hijyeni ve Teknolojisi Anabilim Dalı, Eyyübiye Kampüsü/Şanlıurfa. e-mail: hdurmaz@gmail.com 